\title{
Analysis of Changes in Phosphorylation of Receptor Tyrosine Kinases: Antibody Arrays
}

\section{Sweta Rani and Lorraine 0'Driscoll}

\begin{abstract}
Tyrosine kinases are mainly classified into two groups, as receptor tyrosine kinase (RTK) and non-receptor tyrosine kinase (NRTK). The RTK family of transmembrane ligand-binding proteins are important mediators of the signaling cascade and includes EGFR, PDGFR (platelet-derived growth factor receptors), FGFR (fibroblast growth factor receptor) and the IR (insulin receptor). RTKs comprise 59 members and their structure includes an extracellular ligand-binding domain, a transmembrane domain, and an intracellular domain possessing the tyrosine kinase activity. This chapter focuses on antibody arrays that are basically used to analyse phosphorylation and dephosphorylation of RTKs. Antibody arrays include well-characterized antibodies for profiling, changes in RTK expression, and comparison between normal, diseased, or treated samples.
\end{abstract}

Key words Kinase activity, Cell lysis, Protein arrays, Phosphorylation, Receptor tyrosine kinase

\section{Introduction}

RTK signaling pathways have been associated with various functions including regulation of cell cycle, proliferation, differentiation, and migration [1-3]. Activation of RTKs initiates the signal transduction pathways [4].

This chapter focuses on antibody arrays that are basically used to analyze phosphorylation and dephosphorylation of RTKs. Most of the antibody arrays available comprise either nitrocellulose membranes or transparent 96-well polystyrene plates containing capture and control antibodies. The respective phosphorylated and non-phosphorylated RTKs in sample lysate bind to these antibodies through their extracellular domain and unbound material is washed off. The arrays are then incubated with anti-phosphotyrosine-HRP that sandwiches with phosphorylated RTKs captured on the array. Following second wash these complexes are then visualized by chemiluminescence. Signal generated at each 
1. Isolate total protein from cell lines

2. Prepare the array and reagent for profiling

3. RTKs in sample lysate are captured by antibodies

4. Anti-Phospho-TyrosineHRP Detection Antibody is incubated for 2 hours

5. Protein phosphorylation is determined using signal density
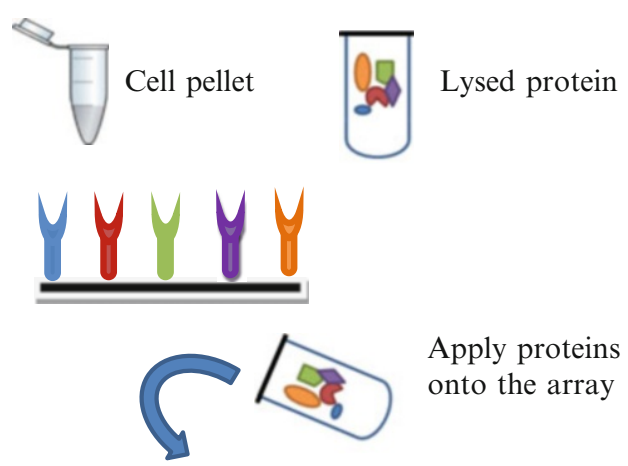

Apply proteins onto the array

Fig. 1 Flow chart of the phosphoprotein array procedure

array spot is proportional to the amount of phosphoprotein bound by each capture antibody. A flow chart is included to guide the readers (Fig. 1).

\section{Materials}

\subsection{Cell Culture}

1. SKBR3 cells (American Type Tissue Collection, Rockville, MD, USA).

2. Trastuzumab-resistant SKBR3 cells: Established by continuous exposure to $1.4 \mu \mathrm{M}$ trastuzumab for 9 months [5].

3. Culture medium: RPMI-1640 medium supplemented with $1 \mathrm{mM}$ L-Glutamine and $10 \%$ foetal bovine serum (FBS).

4. Tissue culture-grade vented flasks (e.g., $175 \mathrm{~cm}^{2}$ ).

5. Trastuzumab (Roche, Penzberg, Germany).

\subsection{Cell Lysis}

1. Lysis buffer (Life Technologies, Carlsbad, CA, USA). Store at $-20{ }^{\circ} \mathrm{C}$ ( see Note 1$)$.

2. Phenylmethylsulfonyl fluoride (PMSF, Sigma-Aldrich, St Louis, MO, USA): Prepare 0.3 M stock in DMSO and store at $-20{ }^{\circ} \mathrm{C}$. 
3. Purified deionized water $\left(\mathrm{dH}_{2} \mathrm{O}\right)$.

4. 20× Protease inhibitor cocktail (Sigma-Aldrich). Store at $-20{ }^{\circ} \mathrm{C}$. Dissolve the contents of the vial in $10 \mathrm{~mL}$ of $\mathrm{dH}_{2} \mathrm{O}$, and then transfer to another container for dilution to $100 \mathrm{~mL}$.

5. Microcentrifuge.

\subsection{Protein Quantification}

\subsection{Phosphoprotein Arrays}

\subsection{Immunoblotting}

1. Bradford Protein Assay (Bio-Rad, Hercules, CA, USA). Store at $4{ }^{\circ} \mathrm{C}$.

2. Bovine serum albumin (BSA). Store at $4{ }^{\circ} \mathrm{C}$. Once in solution store at $-20{ }^{\circ} \mathrm{C}$.

3. 96-Well plates.

4. Spectrophotometer microplate reader.

1. Human Phospho-RTK array (R\&D Systems, Minneapolis, $\mathrm{MN}, \mathrm{USA}$ ): The kit includes array buffer 1, array buffer 2, wash buffer, chemi-reagent 1 , chemi-reagent 2 , anti-phosphotyrosine-HRP detection antibody, 4-well multi-dish, and transparency overlay template. Store the reagents as recommended by the manufacturer ( see Note 2 ).

2. Flat-tip tweezers.

3. Rocking platform shaker.

4. Plastic container with the capacity to hold $50 \mathrm{~mL}$ (for washing the arrays).

5. Plastic transparent sheet protector (trimmed to $10 \mathrm{~cm} \times 12 \mathrm{~cm}$ and opened on three sides).

6. Plastic wrap, paper towels, absorbent wipes.

7. X-ray film and autoradiography film cassette.

8. Flatbed scanner with transparency adapter capable of transmission mode.

1. $4 \times$ Laemmli buffer: $8 \%$ sodium dodecyl sulfate (SDS), $40 \%$ glycerol, 0.25 M Tris-HCl, pH 6.8, 0,04 \% (w/v) bromophenol blue (BPB). Store at $-20^{\circ} \mathrm{C}$.

2. Precast polyacrylamide electrophoresis gels. Store at $4{ }^{\circ} \mathrm{C}$.

3. $10 \times$ running buffer: $0.25 \mathrm{M}$ Tris- $\mathrm{Hcl}, 1.92 \mathrm{M}$ glycine, $1 \%$ SDS, $\mathrm{pH}$ 8.3. Store at room temperature.

4. Prestained molecular weight markers.

5. Mini-slab size electrophoresis system.

6. $1 \times$ Transfer buffer: $23 \mathrm{mM}$ Tris, $175 \mathrm{mM}$ glycine, $20 \%$ methanol.

7. PVDF membrane and blot paper.

8. $10 \times$ Tris-buffered saline (TBS, $10 \times$ ): $100 \mathrm{mM}$ Tris- $\mathrm{HCl}$, $\mathrm{pH} 7.5,1.5 \mathrm{M} \mathrm{NaCl}$. Store at room temperature. 
9. Blocking buffer: $1 \times$ TBS containing $5 \%$ low-fat dry milk or BSA.

10. Washing buffer (TBS-T): $1 \times$ TBS solution supplemented with $1 \%$ Tween-20. Store at room temperature.

11. Antibody dilution buffer: $1 \times$ TBS solution supplemented with non-fat milk/BSA and $1 \%$ Tween-20. Single aliquots frozen at $-20{ }^{\circ} \mathrm{C}$.

12. HRP-conjugated IgG secondary antibodies.

13. Semidry electroblotting system.

14. Enhanced chemiluminescent substrate.

15. X-ray film or digital imaging system.

\section{Methods}

\subsection{Cell Culture and Treatment}

\subsection{Cell Lysis}

1. SKBR3 and their resistant variant are grown in $75 \mathrm{~cm}^{2}$ flask till 60-70\% confluence.

2. Cells are washed twice with PBS.

3. SKBR3 cells and their resistant variant are serum-starved by incubation in serum-free medium for $24 \mathrm{~h}$.

4. Cells are synchronized after serum starvation.

5. To analyze the effect of trastuzumab on RTKs, the resistant cell line is incubated with $2 \mu \mathrm{M}$ trastuzumab in serum-depleted medium for further $24 \mathrm{~h}$.

6. SKBR3 cells are incubated in serum-depleted medium only for further $24 \mathrm{~h}$.

1. Scrape the cells from culture flasks (adherent) or collect cells in PBS by centrifugation (non-adherent).

2. Wash the cells twice with cold PBS.

3 . Remove and discard the supernatant and collect the cell pellet. It can either be stored at $-80^{\circ} \mathrm{C}$ or used straight away.

4. Prepare lysis buffer (thawed on ice) by adding PMSF to a final concentration of $1 \mathrm{mM}$ ( see Note 3 ).

5 . Add reconstituted protease inhibitor cocktail $(250 \mu \mathrm{L}$ per $5 \mathrm{~mL}$ ) to cell lysis buffer.

6. Lyse cell pellet in lysis buffer for $30 \mathrm{~min}$ on ice and vortex at 10 min intervals.

7. Transfer the lysates to $1.5 \mathrm{~mL}$ microcentrifuge tubes and centrifuge at $16,000 \times g$ for $10 \mathrm{~min}$ at $4{ }^{\circ} \mathrm{C}$.

8. Aliquot the clear lysates to clean microcentrifuge tubes. These samples can be used immediately or they can be stored at $-80{ }^{\circ} \mathrm{C}$. Avoid multiple freeze/thaw of cell lysates. 


\subsection{Protein Quantification}

\subsection{Phosphoprotein Arrays}

1. Prepare the stock solution of BSA at a concentration of $\mathrm{lmg} /$ $\mathrm{mL}$ using $\mathrm{dH}_{2} \mathrm{O}$.

2. Dilute the stock solution further to $0.1,0.2,0.3,0.4$, and $0.5 \mathrm{mg} / \mathrm{mL}$ with $\mathrm{dH}_{2} \mathrm{O}$ for protein standards (see Note 4 ).

3. Dilute the protein lysates with $\mathrm{dH}_{2} \mathrm{O}$ up to a volume of $20 \mu \mathrm{L}$ at a ratio of $1: 10$.

4. Diluted lysates and standards $(10 \mu \mathrm{L}$ each) are pipetted in duplicate into each well of a 96-well plate.

5. Dilute the Bio-Rad protein assay reagent at a ratio of $1: 5$ using $\mathrm{dH}_{2} \mathrm{O}$.

6. Pipette $200 \mu \mathrm{L}$ of diluted reagent into each well containing protein and standards.

7. Measure the absorbance at $595 \mathrm{~nm}$.

8. Use the values from the standards to plot a standard curve and to determine the protein content of the samples.

1. Bring all reagents to room temperature before use. Keep samples on ice (see Note 5).

2. Pipette $2.0 \mathrm{~mL}$ of array buffer 1 into each well of the 4 -well multi-dish (provided with the kit). Array buffer 1 is used as a blocking buffer.

3. Using a flat-tip tweezers, carefully remove each array from the protective sheets.

4. Place each array into each well of the 4-well multi-dish with array number facing upward (see Note 6).

5. Place the 4-well multi-dish on a rocking platform shaker and incubate for $\mathrm{l} \mathrm{h}$ at room temperature, rocking the array from end to end in its well.

6. While the arrays are blocking, prepare $50 \mu \mathrm{g}$ of whole-cell lysate by diluting it with array buffer 1 to a final volume of $1.5 \mathrm{~mL}$. The amount of protein needed varies with the cell line used and the level of expression of the protein of interest; therefore optimization is required before using the array.

7. Array buffer 1 is aspirated from the 4 -well multi-dish. Samples are then added onto the 4-well multi-dish and covered with lid.

8. Incubate the samples overnight at $2-8{ }^{\circ} \mathrm{C}$ on a rocking platform shaker (see Note 7).

9. Wash the membrane by carefully removing each array and placing them into individual plastic containers with $20 \mathrm{~mL}$ of $1 \times$ wash buffer ( see Note 8). Thoroughly rinse the 4-well multidish with $\mathrm{dH}_{2} \mathrm{O}$ and dry.

10. Wash each array twice using $1 \times$ wash buffer for $10 \mathrm{~min}$ on a rocking platform shaker (total of three washes). 
11. Prepare fresh $1 \times$ array buffer 2 (see Note 9 ) and anti-phosphotyrosine-HRP detection antibody (see Note 10). Pipette $2.0 \mathrm{~mL}$ of diluted detection antibody into each well of the 4-well multi-dish.

12. Carefully remove each array from its wash container, draining the excess wash buffer from the array. Return the arrays to the 4-well multi-dish containing the diluted anti-phosphotyrosine-HRP detection antibody and cover with the lid.

13. Incubate for further $2 \mathrm{~h}$ at room temperature on a rocking platform shaker.

14. Wash each array as described in steps $\mathbf{9}$ and $\mathbf{1 0 .}$

15. Complete all the subsequent steps without interruption.

16. Carefully remove each membrane from its wash container. Drain excess wash buffer from the membrane by blotting the lower edge onto paper towels. Place each membrane on the bottom sheet of the plastic sheet protector with the identification number facing up.

17. Pipette $1 \mathrm{~mL}$ of the prepared chemi-reagent mix evenly onto each membrane (see Note 11 ).

18. Cover the membrane with the top sheet of the plastic sheet protector and gently smoothed out of any air bubbles. Carefully ensure that chemi-reagent mix was spread evenly to all corners of each membrane.

19. Incubate the membrane for $1 \mathrm{~min}$ in chemi-reagent mix.

20. Take care to squeeze out the excess chemi-reagent mix by positioning the paper towels on the top and sides of the plastic sheet protector containing the membranes.

21. After removing the top plastic sheet protector carefully blot out any remaining chemi-reagent mix by laying an absorbent wipe on top of the membranes.

22. Leave the membrane at the bottom of plastic sheet protector, and wrap it using plastic wrap to cover the membranes, taking care to gently smooth out any air bubbles.

23. Place the membranes with the identification numbers facing up in an autoradiography film cassette (see Note 12).

24. Then expose the membranes using X-ray film for multiple exposure time ranging between 1 and $10 \mathrm{~min}$ (see Note 13).

\subsection{Data Analysis}

1. The positive signals on developed films are identified by placing the transparent overlay template on the array image and aligning it with the pairs of reference spots in three corners of each array. The stamped identification number on the array must be placed on the left-hand side (see Note 14). 
2. Transmission mode scanner and image analysis software are used to collect and analyze the pixel densities on developed $\mathrm{X}$-ray film.

3. A template is created to analyze pixel density in each spot of the array.

4. The signals (pixel density) of the pair of duplicate spots representing each RTK are averaged.

5. For the background value a signal from a clear area of the array or the PBS-negative control spots is selected. The averaged background signal is subtracted from each RTK signal.

6. Corresponding signals on different arrays are compared to determine the relative change in tyrosine phosphorylation of specific RTKs between samples.

7. Fold change are calculated and proteins with highest difference in expression are selected for further validation using immunoblotting.

\subsection{Immunoblotting}

Selected differentially regulated proteins are validated in protein lysates isolated from SKBR3 cells and their resistant variant after treatment.

1. Prepare samples by diluting the protein lysates in $4 \times$ Laemmli buffer and heat them on a heating block at $95{ }^{\circ} \mathrm{C}$ for $5 \mathrm{~min}$.

2. Place the precast gels in electrophoresis device used.

3. Remove the comb and wash the wells to get rid of any trapped bubbles.

4. Load wells with the samples and the molecular markers.

5. Set up the unit and run at constant voltage up to $130 \mathrm{~V}$ to carry samples through the stacking gel, and then increase to $150 \mathrm{~V}$ to run through the resolving gel.

6. Turn off the power supply immediately after the Lamelli buffer has run off the gel.

7. Cut a sheet of PVDF paper to the size of the gel size and activate the membrane for $1 \mathrm{~min}$ using methanol. Transfer the activated PVDF membrane in another tray filled with transfer buffer. Blot papers are soaked in transfer buffer.

8. Hold the cassette in one hand and use the comb to separate the plates. Loosen the gel and carefully cut and remove the stacking gel with a blade. Transfer the gel into a tray containing transfer buffer.

9. Transfer cassette is assembled by laying the PVDF membrane on the top of the blot paper and then the gel on top of the membrane. Place another blot paper on top of the gel, roll with a roller to make sure that no air bubbles exist between gel and the membrane. 
10. Close the transfer cassette, connect to the power supply and begin transfer, with a constant current of $200 \mathrm{~mA}$ for $1 \mathrm{~h}$.

11. Disconnect the power supply after an hour and disassemble the transfer cassette. Remove the PVDF membrane and check for the prestained markers bands clearly visible on the membrane.

12. Block the membrane by incubating it in blocking buffer for $1 \mathrm{~h}$ at room temperature on a rocker with gentle shaking.

13. Wash the membrane three times using TBS-T.

14. Incubate the membrane for $1 \mathrm{~h}$ at room temperature or overnight at $4{ }^{\circ} \mathrm{C}$ (depending on the manufacturer's instructions) with primary antibody by gentle shaking.

15. Wash the membrane three times with TBS-T for 10 min with vigorous shaking.

16. Freshly prepared secondary antibody solution is added to the membrane for $\mathrm{l}$ h at room temperature with gentle shaking. The secondary antibody solution can be reused if stored appropriately.

17. Wash by vigorous shaking three times with TBS-T for $10 \mathrm{~min}$.

18. Mix the ECL reagents together at a ratio of $1: 1$ immediately before use and evenly add the mix to the blot for $5 \mathrm{~min}$.

19. Remove excess ECL.

20. Expose the membrane using film or digital imaging.

\section{Notes}

1. Lysis buffer should be thawed on ice and working aliquots stored at $-20{ }^{\circ} \mathrm{C}$ to avoid repeat freezing and thawing.

2. Return unused membranes to the foil pouch containing the desiccant pack. Reseal along entire edge of the zip-seal. May be stored for up to 3 months at $2-8{ }^{\circ} \mathrm{C}$ and used within expiry date.

3. PMSF is very unstable and must be added just prior to use.

4. BSA stock and dilution can be reused if stored properly in $-20{ }^{\circ} \mathrm{C}$ and thawed on ice.

5. To avoid contamination, wear gloves while performing the procedures.

6. When array membrane comes in contact with array buffer 1 the blue dye will disappear from the spots. The capture antibodies are retained in their specific locations.

7. Incubation time can be optimized depending on the abundance of protein present in the samples.

8 . Bring the $25 \times$ wash buffer concentrate to room temperature and if crystals are formed shake gently till all the crystals have 
completely dissolved. Dilute $40 \mathrm{~mL}$ of $25 \times$ wash buffer concentrate into $960 \mathrm{~mL}$ of $\mathrm{dH}_{2} \mathrm{O}$.

9. Prepare this buffer fresh before each use by adding $2 \mathrm{~mL}$ of concentrated array buffer $8 \mathrm{~mL}$ of $\mathrm{dH}_{2} \mathrm{O}$.

10. Detection antibody must be diluted using $1 \times$ array buffer 2 immediately before use. Prepare only as much detection antibody as needed to run each experiment.

11. Chemi-reagent mix is prepared by mixing chemi-reagents 1 and 2 in equal volumes within $15 \mathrm{~min}$ of use. The mixture must be protected from light. $1 \mathrm{~mL}$ of the resultant mixture must be prepared, as using less than $1 \mathrm{~mL}$ of chemi-reagent mix per membrane may result in incomplete membrane coverage.

12. Use clean autoradiography cassette.

13. Multiple exposure time is recommended to capture the low signal as well.

14. Reference spots are included to align the transparency overlay template and to demonstrate that the array has been incubated with the anti-phospho-tyrosine-HRP during the assay procedure.

\section{Acknowledgements}

Science Foundation Ireland's funding of MTCI [08/SRC/ B1410]; the Higher Education Authority's PRTLI Cycle 5 support of TBSI; Irish Cancer Society's support of Breast-PREDICT [CCRC13GAL]; and the Health Research Board [HRA_POR/ $2013 / 342]$.

\section{References}

1. Linger RM, Keating AK, Earp HS et al (2008) TAM receptor tyrosine kinases: biologic functions, signaling, and potential therapeutic targeting in human cancer. Adv Cancer Res 100:35-83

2. Grassot J, Gouy M, Perriere G et al (2006) Origin and molecular evolution of receptor tyrosine kinases with immunoglobulin-like domains. Mol Biol Evol 23:1232-1241

3. Lemmon MA, Schlessinger J (2010) Cell signaling by receptor tyrosine kinases. Cell 141: 1117-1134
4. Koytiger G, Kaushansky A, Gordus A et al (2013) Phosphotyrosine signaling proteins that drive oncogenesis tend to be highly interconnected. Mol Cell Proteomics 12: 1204-1213

5. Konecny GE, Pegram MD, Venkatesan N et al (2006) Activity of the dual kinase inhibitor lapatinib (GW572016) against HER-2-overexpressing and trastuzumab-treated breast cancer cells. Cancer Res 66: 1630-1639 